\title{
The Extent To Which Social Studies Teachers Supreme Basic Stage In Aqaba Governorate My Skills For Decision-Making And Solving Classroom Problems
}

\author{
Doha I. Tarawneh \\ Department of Arabic Language, Faculty of Langauge, \\ University of Jordan/Aqaba, Jordan
}

doi: 10.19044/esj.2016.v12n8p271 URL:http://dx.doi.org/10.19044/esj.2016.v12n8p271

\begin{abstract}
This study aimed to reveal the extent to which social studies teachers basic upper stage in Aqaba Governorate of my skills to make decisions and solve classroom problems in Jordan, the study population consisted of all social studies teachers basic upper phase in the province of Aqaba in Jordan; where formed the sample of 49 teachers of the study population, of whom 18 teachers and 31 teacher, spread over the sample schools were distributed a questionnaire designed for this purpose in advance after the arbitration process of conducting a tribal them, where the collected data were statistically analyzed where they were entered into a computer and used a researcher at the process analysis Statistical Package for Social Sciences (SPSS) and software (Excel) .quart researcher extracted the arithmetic means, and standard deviations for each paragraph and each area of study, as well as the researcher used t-test. Results of averages, standard deviations, and showed that skill for decision-making at the highest arithmetic averages and standard deviations in favor of females to males. The study concluded with recommendations in their entirety focus attention on the need for the development of teachers' ability to deal with classroom problems and taking into account the situation of students as well as giving Thinking greater share of decision-making in the field of teacher preparation.
\end{abstract}

Keywords: Decision-making, classroom problems

\section{Introduction}

The process of developing the educational process depends on the improvement and development of basic inputs. The teacher remains the key element of these inputs in addition to other inputs. Katalib and other curriculum have reflected the development and improvement of the 
performance of the teachers of education directly. This is with the aim of improving the process, and developing and increasing its effectiveness. However, there are many scientific, behavioral, and psychological theories at the global and Arab level, which focuses on improving the performance and behavior of the teacher as the most important inputs of the educational process. In addition, it also acts as a guide directed to students (Youssef alAhmed, 2001).

In light of the change that the world is witnessing about technological progress and the explosion of knowledge, obtaining a large amount of information has become more difficult. Therefore, it is necessary to develop interest in the personality of the teacher, and work on the development of their thinking skills. Consequently, the development of various skills to increase teacher's ability to deal with the students, resolve classroom problems they are facing, work on student's assessment, and make decision "as to solve problems is of great importance in the lives of all individuals in an ongoing basis" Mustafa (2002: 123).

\section{The Problem of the Study}

The teacher is the cornerstone of the educational learning process. As a result, all its elements have to be in place in order to develop the process and all the elements that are working on the development of the teacher. This is put into consideration especially since studies have shown that $60 \%$ of the success of the educational process in all its dimensions is the responsibility of the teachers alone. Furthermore, this is accompanied with other forms of dimensions such as management all combined, curriculum, books and school learners, and the possibilities of a $40 \%$ success rate of the educational process (Farra, 1996).

Furthermore, there is an increasing complaint and problems at all stages of education on the low level of training programs offered to the teachers and the lack of responsiveness to the demands of the teachers. Thus, this helps them in meeting the demands of the learners. Also, it makes those programs meet the needs of teachers and raise their level in helping them to increase their ability to make decisions and solve classroom problems. Therefore, the following question is used for this study:

- What is the extent to which teachers of social studies core upper stage in Aqaba Governorate uses the skills for decision-making and solving classroom problems from their point of view?

- Are there any significant differences among teachers of social studies basic stage which is supreme in the amount of possession of skills, decision-making, and in solving classroom problems from their point of view in public schools in the Directorate of Education of the province of Aqaba attributed to the sex of the teacher (male, female)? 


\section{Procedural Definitions}

Social studies teacher is a person appointed as an official from the Ministry of Education in public schools in Jordan. He/she is fully responsible for the achievement of the desired educational goals for social studies.

Decision-making and social studies teacher assigned by the Ministry of Education in an official capacity has the ability to take a stand or choose a particular solution of a particular case. They also put the problem of falling in. Therefore, they can benefit from this solution or position in their working lives and science to raise the efficiency of teaching students.

Solving classroom problems through the teacher's ability to deal with the conduct of the educational process might be either positive or negative. However, Menahiha measures within the classroom to ensure that information in a manner is optimized.

\section{Determinants of the Study}

This study was limited to teachers of social studies core upper stage in Aqaba for the academic year 2013/2014.

The study was confined to identify the training needs of teacher's skill and decision-making skill to solve classroom problems. This was done by answering the paragraphs of the questionnaire developed by the researcher.

\section{Previous Studies}

A study was conducted by Jawarneh in 2001, which targeted the detection of social studies teachers training needs in the province of Aqaba. From this point of view, the study tries to answer the following questions:

- What are the social studies teachers training needs in the province of Aqaba from their point of view?

- Does the needs of the social studies teachers in the province of Aqaba differ in terms of sex, qualification, experience, and specialization?

The study sample consisted of all social studies teachers in the province of Aqaba. However, the researcher identifies the training needs which consisted of 74 items distributed on the following areas: objectives, content, activities and methods, techniques, Calendar, classroom management, and organization.

Applied researcher questionnaire on the sample after doing validity and reliability have procedures. However, this was done after the work on the collection and analysis of information statistically. They found the results to respond to the needs of social studies teachers in the province of Aqaba in all areas of the questionnaire. Subsequently, these areas were sorted by averages calculation as follows: calendar, activities and methods, techniques, goals, content, classroom management, and organization. Consequently, the 
study also created a statistically significant difference between the averages of estimates answer to the study sample (social studies teachers). These answers are about their training needs due to gender, qualification, and specialization at all levels and in favor of the males. Therefore, results showed no statistical significant differences between the averages due to the variable experience.

Moreover, the study aimed to detect the needs of social studies teachers in using the original sources in history teaching skills at the upper basic stage of UNRWA schools in Jordan. The goal was to develop a questionnaire composed of 44 items distributed on seven areas. In addition, the study sample include Vtkont (103 ) teachers of social studies in the upper basic stage of UNRWA schools in Jordan.

The results of the study compared to the needs of the college social studies teachers were medium with a percentage of $68 \%$. Thus, the area of skills obtained revealed the historical truth and the skills of detecting the relationship between cause and effect and skills classification historical events in time and space. The skills of judgment and decision-making were in high needs. On the other hand, the area of skills used in the curriculum historical research in the study of historical research and research skills for historical evidence were the needs of social studies teachers. Thus, they were no significant differences due to gender and the experience of the teacher. Consequently, taking a teacher training course also showed the presence of statistically significant difference due to scientific qualified differences, e.g. the teacher between bachelor holders of BA + Higher Diploma in favor of bachelor + Higher Diploma.

As was indicated, there was a statistically significant difference due to the specialization between teacher specialization campaign history teacher and the field of social studies and history in favor of specialization differences. The study recommended not be assigned to non-history teachers who taught the history of other disciplines. Thus, it encourages social studies teachers who hold a bachelor's degree or a Higher Diploma to hold workshops for history teachers about the skills which reveals the historical truth. This includes the skills of detecting the relationship between cause and effect, and the skills of classification in time and space historical events.

A study conducted by Nouri (1997) which is aimed at detecting managers, determined the basic training needs of schools, the degree of availability, and its impact on the decision-making process. This is achieved by answering the following research questions:

- What are the basic training needs of school administrators in the northern governorates in the West Bank, as seen by managers?

- Is there any statistically significant differences in the estimates of training managers for their needs due to gender, educational qualification, 
the Supervisory Authority, monthly income, the number of students in the school differences, the number of teachers at the school, school location, and years of experience in management?

The study population consisted of principals of government basic schools of the UNRWA in the West Bank. They were selected using randomly stratified systematic sampling. A questionnaire for the training needs was developed by a researcher based on the identification of Randall. After, the validity and reliability of the questionnaire, consisting of a number of areas depending on the steps of decision-making (define the problem, information collection, information analysis, decision-making), is been distributed. Therefore, after the information has been collected and analyzed statistically, the results showed percentages to respond to areas of the study as seen by managers. The results showed that there were no statistically significant differences due to the variable sex, Qualifications Authority supervisor, monthly income, the number of students in the school, the number of teachers at the school, the location of the school, the years of experience in management, the training needs, and the degree of availability.

\section{Analyzing the Results of the Study The Study Variables}

The study variables include both the independent and dependent variables as shown below:

First, the independent variables include:

- Gender has two categories (Male, Female).

- Qualification (Diploma, Bachelor, Higher than BA)

- Experience (less than a year, from one year to five years, more than five years)

Second, the dependent variables include:

Estimate the study sample (teachers of social studies core upper stage) through their responses to the questionnaire prepared for the paragraphs of this study.

Table (1)

The distribution of the study sample by

The study variables

Gender Total

Male 18

Female 31

Total 49

The Study Tool

The researcher prepared a questionnaire study on the assessment of teachers of social studies core upper stage. This has to do with decisionmaking skills and solving classroom problems after returning to the 
theoretical literature and previous studies on the subject of the search. The questionnaire consists of two parts. The first contains personal information including independent variables, namely: sex, qualification, and experience; while the second part of the questionnaire consists of areas of special training needs, namely: decision-making, problem solving, and classroom management. The result of the study was indicated on a Likert scale questionnaire as follows: always, often, sometimes, and rarely which represents the tags $4,3,2$ and 1 , respectively.

\section{Believe Tool}

The researcher introduced a questionnaire to a group of specialists in Curriculum and Instruction, ESF, Mutah University, and a number of supervisors in the same specialty. However, those with experience in the field of education ensure the veracity of the tool in terms of: the subordination of the paragraphs of the field, linguistic and drafting, clarity of paragraphs, and any other observations, amendment, or deletion. In addition, it has obtained the researcher views, comments, and suggestions so that the tool is composed of 35 items distributed on two areas. These areas include amending some paragraphs based on the consensus of the arbitrators, and adopting a researcher at the consensus (86\%) of the arbitrators. Subsequently, this became the Number of paragraphs (35) items distributed on the fields of study: decision-making (17) paragraphs and classroom problems (18) paragraphs (Annex (1)).

\section{The Stability of the Tool}

To check the stability of the tool, the researcher uses the Cronbach Alpha internal consistency coefficient for each area. On one hand, it reaches the reliability coefficient for the first field: decision-making (0.78) and the second area of Elsafayh problems (0.86). On the other hand, it reaches the stability internal consistency of the birth of a whole coefficient (0.896). However, this can be seen in Table (2).

Reliability coefficient values by Cronbach equation alpha fields of study and the instrument as a whole

Number field value reliability coefficient

1 Decision 0.78

2 resolve classroom problems 0.86

7 total 0.896

Table (2) above indicates the reliability coefficients for fields of study individually as well as the stability of the questionnaire as a whole with the coefficient reaching 0.78 . The reliability coefficients for the areas ranged at 0.78 for the field (decision-making skills) and 0.896 for the area (to 
solve classroom problems). However, these transactions have high stability and are acceptable in such studies.

\section{The Study Measures}

The researcher followed the implementation of the study through the following procedures:

- The researcher studies the problem and determines questions and variables and their statistical method.

- The questionnaire was developed through the use of educational literature and previous studies, and the resolution amounted to paragraphs (35). The veracity of the tool through a presentation to a group of arbitrators and numbered (11) arbitrator was ascertained.

- Ensure the stability of the tool by calculating the reliability of Cronbach alpha coefficient which amounted to 0.896 .

- The questionnaires were distributed to teacher's specialization of Social Studies basic upper stage in public and private schools totaling 49 teachers. The questionnaire are in two parts, Part I which included personal information, and part II which include the areas of the questionnaire such as decision-making (17) paragraph, and the field of solving classroom problems (18) paragraph.

- The researcher answer questionnaires collected after members have studied them after a period of time and were entered into a computer.

- Conducted a research with appropriate statistical analysis, and then displays the results, interpretation, and the discussion.

\section{Statistical Treatment}

- After collecting the data, it was entered by the researcher into the computer using the Statistical Package for Social Sciences analysis (SPSS) software or Microsoft Excel.

- The researcher extracted the arithmetic means and the standard deviations for each paragraph and each area of study. Also, the researcher made use of t-test.

- Results of the Study and Discussion

- First Question: What is the extent of teachers of social studies core upper stage in Aqaba Governorate skills in decision-making and solving classroom problems from their point of view?

- The researcher extracted the arithmetic means and the standard deviations for each area of the study. In addition, it extracts the paragraphs of each area in a descending order as shown in Tables 1 and 2.

- It adopted the researcher following the test to judge the degree of importance of training needed. Consequently, this can be seen in Table 1 below: 
Table (1)

Averages and standard deviations of the vertebrae questionnaire

The ideal arithmetic average of the sequence of a standard deviation

1. To diagnose the problem before making a decision around 3:56 0:53

2. To give enough time to think about the problem 3.440 .62

3. Develop a set of alternatives (solutions) and the appropriate selection of the most appropriate alternative to solve the problem 3.220 .69

4. Anticipate the reactions if the decision Atkhave 2.920 .87

5. Gather information about the problem 3.360 .63

6. Follow-up the decisions taken to solve problems 3.20 .79

7. Modify the resolution when needed in accordance with the approved Lajrat. 3.060 .80

8. Become aware of the problem with its various dimensions 3.280 .81

9. Setting goals that can be achieved by adopting resolution 3.320 .79

10. Determining the expected results for each alternative 3.240 .82

11. Evaluation of the expected advantages and disadvantages to replace 3.120 .79

12. Study implications of the decisions 3.440 .78

13. Decisions individually 2.90 .96

14. Enkhaz same as the previous decision to solve a problem in the event of a repeat position 2.71 .10

15. Feelings that the decisions gave me a sense of courage 3.560 .85

16. Discernible decline at some of the decisions 2.620 .95

17. Influenced by psychological situation during Atkhave decision 1.960 .96

1. Knowledge of the laws of classroom behavior 3.490 .70

2. ml work appreciated by others feelings and attitudes 3.490 .67

3. Respond quickly to the bad behavior of the student 3.370 .62

4. Impartiality for a certain class of students 3.470 .70

5. Work to give a clear and specific instructions 3.550 .60

6. Justice and consistency in the application of the laws 3.570 .72

7. Accept the opinions of others no matter how contrary to Ray 3.490 .90

8. Dimensions for the student air aggressive competition 3.590 .86

9. Proper training on how to deal with classroom problems 3.411 .02

10. Review of the laws of classroom behavior and a 3.10 1.27 League

11. Training on how to maintain order in emergency situations 3.311 .30

12. Cognitive on what is going on (being) in the classroom 3.551 .36

13. Sufficiency gesture, and references to the notice by the student's satisfaction for his behavior 2.961 .60

14. Move away from the use of threats and intimidation phrases 3.121 .82

15 Any personal and individual characteristics of students identified 3.141 .83

16. Address urgently the problems that occur inside the classroom room 3.201 .97

17. Continue to switch the places students sits 2.632 .23

18. Communicate with the students and work, and friendly relations with them. 2.692 .41

Table (1) indicates that the averages ranged between paragraphsresolution (1.96) of paragraph (17) "influenced by psychological situation during Atkhave decision" with a standard deviation of 0.96. However, I got paragraph (25) to the arithmetic average (3.94) with a standard deviation of 0.86. Furthermore, the researcher studies the averages and the standard deviations for each of the areas. The results are as follows: 
Table (3)

Averages and standard deviations for the study sample answers for each area of the study in ascending order Rank number field field arithmetic average standard deviation

$2 \quad 3.01 \quad 0.91$ classroom problems
3.29 3.20
0.82 0.85

Table (3) indicates the averages and standard deviations fields of the study Monday values. However, it notes that the first area (the decision) got the lowest average arithmetic which was 3.01. Also, it has a standard deviation of 0.91 , while the second area (solution to classroom problems) at the highest arithmetic average was 3.29, with a standard deviation 1.16. The researcher believes that the solution to the problems of classroom is Almhart which has to be the most important for teachers of mastery. Consequently, this is in line with the findings of this study, where he sees that teacher needs to master these skills compared with other area which is not less important.

\section{Results Based on Analysis}

Table (4)

Averages and standard deviations for the study sample answers for the paragraphs of the first domain/decision-making in a descending order Rank paragraph number, paragraph $\backslash$ field Atkhamalaqrar average standard deviation

11 diagnose the problem before making a decision around 3:56 0:53

215 feeling that the decisions give me a sense of courage 3.560 .85

32 to give enough time to think about the problem 3.440 .62

412 study implications of the decisions 3.440 .78

55 gather information about the problem 3.360 .63

69 setting goals that can be achieved by adopting resolution 3.320 .79

78 perception problem with its various dimensions 3.280 .81

810 Almnoukah determine the results of each alternative 0.823 .24

93 develop a set of alternatives (solutions) and chose the most appropriate alternative to solve the problem 3.220 .69

106 follow-up to the decisions taken to solve problems 3.20 .79

1111 evaluation of the expected advantages and disadvantages to replace 3.120 .79

127 modify the resolution when needed, in accordance with the approved Lajrat. 3.060 .80

134 anticipate the reactions if the decision Atkhave 2.920 .87

1413 decisions individually 2.90 .96

1514 take the same the previous decision to solve a problem in the event of a repeat position 2.71 .10

1616 discernible decline at some of the decisions 2.620 .95

1717 influenced by psychological situation during Atkhave decision 1.960 .96

\section{Results Based on Analysis}

The deployment of the table (4) that the idea is "to diagnose the problem before making a decision around," received the highest average arithmetic of 3.56 with a standard deviation of 0.53 . While I got paragraph 
"influenced by psychological situation during Atkhave of the resolution" at the lowest arithmetic average of 1.96 with a standard deviation of 0.96 . Thus, the researcher stated that teachers need more training to diagnose the problem well and identify various causes that lead Baldharaurerh to make the right decision around. Most of the teachers are separating themselves from their emotions to help them make decisions. They are affected by the degree of closeness to the students during Amlbh monitoring tags, or correct answers to books.

Table (5)

Averages and standard deviations for the study sample answers for the paragraphs of the second area / classroom problems

Rank paragraph number, paragraph / field of solving classroom problems amid deviation

18 dimensions for the student air aggressive competitive 3.590 .86

26 Justice and consistency in the application of the laws 3.570 .72

35 work to give clear and specific instructions 3.550 .60

412 cognitive what is going on (being) in the classroom 3.551 .36

51 familiarity with the laws of classroom behavior 3.490 .70

$62 \mathrm{ml}$ work appreciated by others feelings and attitudes 3.490 .67

77 accept the opinions of others no matter how contrary to Ray 3.490 .90

84 impartiality for a certain class of students 3.470 .70

99 proper training on how to deal with classroom problems 3.411 .02

103 respond quickly to the bad behavior of the student 3.370 .62

1111 training on how to maintain order in emergency situations 3.311 .30

12 Average second area to solve problems 3.290 .82

1316 address urgently the problems that occur inside the classroom room 3.201 .97

1415 Any personal and individual characteristics of students identified 3.14 1.83

1514 move away from the use of threats and intimidation phrases 3.121 .82

1610 review of the laws of classroom behavior and a 3.10 1.27 League

1713 sufficiency gesture, and references to the notice by the student satisfaction for his behavior 2.961 .60

1818 communicate with the students and work and friendly relations with them. 2.692 .41

1917 continue to switch the places students sits 2.632 .23

The table indicates that paragraph (8): "keep students on air competitive and aggressive," I received the highest average arithmetic was 3.59 with a standard deviation of 0.86 . Paragraph (17) "continuous switch in the sitting students" have a less arithmetic average at 2.63 with a standard deviation of 2.23. The researcher states that teachers need to be trained to keep students from aggressive behavior process. Also, they need to possess skills and knowledge of the psychological and emotional situation of the students to keep them away from aggressive feelings (Crane, Ktattenh , AbuAssad, 2011). Furthermore, they need to acquire and perform rehearsals of these skills. Hence, intuitive students do not need a lot of training for mastery.

Second Question: Is there a statistically significant differences at the level of significance $(\alpha \leq 0.05)$ when teachers of social studies basic stage 
supreme in the amount of possession of skills in decision-making and solving classroom problems from their point of view in public schools in the Directorate of Education of the province of Aqaba is attributed to sex Teacher (Male, Female)?

The researcher extracted the averages, standard deviations, and the use of t-test to determine potential differences with statistical significance of the training needs due to gender at the level of significance $(\alpha \leq 0.05)$. Thus, this can be seen in Table (7).

Table (7)

Averages, standard deviations, and test (v). The effect of sex on the fields and the tool as a whole

Gender field average number Arithmetic deviation

The standard value $(\mathrm{T})$ level

Significance

Decision-making said 18 3,212 0.36 3,075 0.04 * Female 312.890 .55

Classroom problems Male 183.38 0.28 0.132 0.191 3.22 0.48 31 Female

Table (7) indicates that the differences are statistically significant by t-test in the first field by only a decision. This is donated with the sign (*) as shown in the table significance level less than $0.05 *$. Consequently, we note that the difference in favor of males also shows values of the arithmetic mean of the two averages. In the second area, "solving classroom problems" were not statistically significant at the level of the differences $(\alpha \leq 0.05)$.

They are performing the process quickly; and oftentimes, their decisions were improvisational as many of the teachers were students. Thus, they began their improvisational way of proving their strength as stated by Gilligan (Gilligan) contained in Abu Ghazal (2006). However, they are differences between sexes regarding the way both of them look the same in its relations with others. Males see themselves more often that they are independent or separated from others, while females see themselves through their relationships with others.

In studying the qualification of the teacher's training needs on the impact of the researcher using the contrast unilateral analysis to test the hypothesis, there were no statistically significant differences due to the qualification of teachers in the degree of their need for training on skills in decision-making and solving classroom problems from their point of view, Thus, the results is shown in table (8) below. 
Table (8)

Unilateral analysis of variance (ANOVA) to demonstrate the vulnerability of more earnestly teachers for training and scientific qualification for teachers

Sum of squares freedom square degrees of the average value of P Msnoy significance

Classroom problems between 20.2861 .6570 .5720 .202 Groups

Within 467.9410 .173 Groups

Total 8.51348

Decision-making between 20.1810 .0910 .5930 .557 Groups

Groups within 7.018460 .153

Total 7.19948

Table (8) indicates that the differences are not statistically significant at the level of significance $(\alpha \leq 0.05$ (i.e. the teachers and the parameters are not affected by their need for training for different qualifications). The reason for this may be due to the skills by the fact that solving classroom problems and decision-making may not be influenced by the educational level of the teachers as much as it is influenced by personal Basmathm, classroom environment surrounding them, the level of the students and their needs, the general atmosphere of the school administration, and what is prevailing in the school.

To study the effect of experience on the teachers 'needs for training from their point of view, the researcher uses the contrast unilateral analysis to test the hypothesis. Consequently, there were no statistically significant differences due to the teachers' expertise in the degree of their need for training on skills of decision-making and in solving classroom problems. The results is shown in Table (9).

Table (9)

Unilateral analysis of variance (ANOVA) to demonstrate the vulnerability of more earnest training experience for teachers

Domain sum of squares freedom square degrees of the average value of P Msnoy significance

Classroom problems between groups 10.4782 .7940 .4780 .101

Groups within 8.035470 .171

Total 8.51348

Decision-making between groups 10.0960 .0960 .6360 .429

Groups within 7.103470 .151

Total 7.19948

Therefore, it should be noted that from table (9), the experience does not affect the need for teachers to train at the level of significance $(\alpha \leq 0.05)$. What was expected is that the teacher's least experience will show the biggest desire in their need for training. The results of this study confirm that the teachers regardless of their experience had a continuous need for training in all of the decision-making process. Furthermore, they resolve classroom problems convergent levels. This goes back to the great technological development and progress in all walks of life. As a result, teachers requires 
more training in order to keep up with the times and move with the rapid progress of the economy, especially the administrative, educational, and scientific aspect.

\section{References:}

Abu Ghazal, Sid (2006). Theories of human development and educational applications, i 1, Dar march, Amman, Jordan.

Al-Ahmad, Yusuf Rdainah, Hmam (2001). Teaching methods and curriculum means style. I 1 Amman: Dar curriculum.

Jawarneh, Haitham (2001). For social studies teachers training needs in the province of Aqaba from their point of view, his master, Yarmouk University, Irbid.

Mourning, Yousef Jaafar (2010). Construction of a proposed training program to develop the managerial skills of the leaders of the educators in school districts in Kuwait in the light of their training needs, Master Thesis, University of the Middle East, Jordan.

Ktattenh, Sami Abu-Assad, cranes, and conscience (2001). The Principles of Psychology, i 1, Dar march, Amman, Jordan.

Khaza'leh, Saad Awad (2001). The Islamic education teachers training needs in Mafraq, what message? Jstar, Al al-Bayt University.

Eldridge, Mohammed Mohammed Jihad sentences (2005). Teaching mini configuration and professional development for teachers, i 1, University Book House, the eye.

Sabih, Nabil Ahmed Amer (1981). Studies in the preparation and training Amwaliman.t 1. Anglo-Egyptian clerks.

Impotent, Fouad, Nashwan, beautiful (2005). The development of teachers' performance in the light of the school program as a center of the International Development Relief Agency in Gaza, the Sixth Scientific Conference for Sustainable Development of Arab professional teacher, Cairo University.

Farra, Farouk Al Hamidi (1996). Calendar programs, in-service teacher education Sassi in the Gaza Strip / Palestine. Al-Azhar University Journal (Humanities), vol 1, p 2, S123-155.

Mustafa, Fahim (2002). Thinking skills. I 1. Cairo: Dar distribution.

Nouri, Ibrahim Abdulla (1997). Managers basic school training needs and the degree of availability, and its impact on the decision-making process, the study of MS, Bir Zeit University, Palestine. 